\title{
A Brand Equity Driving Model Based on Interaction Quality
}

\author{
An $\mathrm{Yan}^{1, \text { a }}$, Juanjuan Chen ${ }^{2, b}$ \\ ${ }^{1}$ School of Management, Hefei University of Technology, Hefei, Anhui, 230009, China \\ ${ }^{2}$ School of Management, Hefei University of Technology, Hefei, Anhui, 230009, China \\ aemail:yananseu@163.com, bemail:1049927549@qq.com
}

Keywords: Interaction quality; Brand recognition; Brand emotion; Brand loyalty

\begin{abstract}
Brand equity, whose essence is the result of constant interaction between enterprises and customers, is important assets for enterprises. In this study, the concept of interaction and interactive marketing was defined and dimensions of brand equity were divided more clearly. A brand equity driving model was proposed and tested based on interaction quality. The results show that interaction quality has a significant positive impact on brand equity; enterprise- customer interaction quality has positive influences on all factors of brand equity; employee- customer interaction quality has prominent influences on brand image and brand experience.
\end{abstract}

\section{Introduction}

As a symbol of different from other products or service, brand is the foundation of enterprise sustainable development. With the increasing competition and information transparency in the market, the new competition environment make the enterprise realize the value of brand and regard it as an important part of intangible assets, thus caused the marketers and scholars to study brand equity and its influence factors. Brand equity is the intangible assets establishing in the long-term operations and its existence is results of interaction between enterprise and customers. Interaction quality affects customers' evaluation to brand directly, so it is an important driving factor for brand equity. The new brand concept based on the experience says the process of brand formation is a type of dynamic experience process to the brand and all things for customers. In the era of experience economy, interaction puts forward the new content to brand management. In order to analyze the role of interaction quality in brand equity, this paper focused on the interaction process among enterprises, employees and customers, then built the brand equity driven model based on interactive quality, and tested the model through survey data from the domestic automobile brand. I hope the paper can offer reference for improving interaction process, strengthening the effect of interactive marketing and further enhancing the brand equity.

\section{Literature Review}

Interaction and Interaction Quality. Interaction is a synchronous and interdependent behavior in two or more participants. The study of interaction earlier originates from service. As new economy era is coming, the boundaries between physical products and service are becoming more obscure, and customers pay more attention to comprehensive interaction process and interaction quality in physical brand. Bateson ${ }^{[1]}$ (1985) put forward that interaction constitute by customer, employee and enterprise, so it produced three forms of interaction: employee- customer interaction, enterprisecustomer interaction, enterprise- employee interaction. He stressed that only focusing on interaction among customers, employees, and enterprises at the same time can achieve better interaction effect. Ambler $^{[2]}$ extended bodies of interaction, and argue enterprise brand equity include multiple subjects such as enterprises, employees, customers and other stakeholders, among the most important is enterprises, employees, customers.

Interaction quality decides customers' regarded internally to enterprise after interaction. It is the relevance and consistency of enterprises, employees and customers about brand behavior and concept, and high correlation and consistency will have a significant impact on brand equity ${ }^{[3]}$. 
Brand Equity. There is no unified definition of brand equity at present, and most scholars define it from the perspective of customers. Kim ${ }^{[4]}$ (1990) claimed brand equity evoke customers' perception, feelings and association, and also influent customers' decision. Keller ${ }^{[5]}$ (1993) further emphasized the concept of 'brand equity based on the customer'. He pointed out the essence of the brand equity is customers ' different response to brand marketing activities based on brand knowledge, which reflected in customer's perception, preference and behavior. Domestic and foreign scholars did much research on brand equity model from different perspectives. Gil et al. ${ }^{[6]}(2007)$ held brand awareness, perceived quality, brand association and brand loyalty are four dimensions of brand equity, and constructed a brand equity model based on consumer perspective. Feng Zhang ${ }^{\text {[7] }}$ (2011) built a brand equity constituted model based on the theory of cognitive. Brand equity was divided into customer perception, customer emotion and customer behavior in this model.

In conclusion, brand equity is customer s' different response in cognition, emotion, and behavior to a product or brand. Customers' brand perception can cause customers' emotional change, and then produce the behavior associated with the brand. After that companies will carry out brand marketing activities according to customers' different emotional change and behavior response. Thus interaction between the customer and brand was established.

\section{Research Hypothesis and Model}

The Dimensions of Brand Equity. Studying brand equity from the perspective of interaction quality we can find customers have different response to brand marketing activities due to differences of interaction quality in the process of contacting with brands, which reflected in the three levels of brand recognition, brand emotion and brand loyalty. For brand recognition, there are three kinds of customer demand of external basic requirement, the inherent pleasure, and self-improvement and social identity. So this paper argues that brand recognition contains three basic elements, brand function, brand experience and brand image. For brand emotion, lots of scholars like Guihua $\mathrm{Li}$ and Hongliang $\mathrm{Lu}$ et al. ${ }^{[8]}$ (2010) provided brand promise is the key elements of brand emotion. In addition, brand attachment, a unique bond between customers and brand, is an important emotional source of brand equity. For brand loyalty, it is the customers' long-term repurchase intention and behavior to the brand, and most scholars divided brand loyalty into attitude loyalty and behavior loyalty.

On the basis of reading literature home and abroad, according to the basic logical framework of 'recognition- emotion- behavior' from the attitude theory, the dimensions of brand equity are summarized as brand recognition, brand emotion and brand loyalty, and extract seven basic elements of brand function, brand experience, brand image, brand promise, brand attachment, attitude loyalty and behavior loyalty.

The Dimensions of Interaction Quality. Interaction refers to the process and result of communication between enterprises and other interactive participants through participate in interdependent activities in this paper. Therefore, in order to realize the interests of enterprises and stakeholders, enterprises make use of a variety of interactive methods and put other interactive participants into value creation process to create value collectively, and make every participator obtain a degree of satisfaction in interaction, and improve enterprises' core competence through series of communications like event marketing, promotion, pricing. This purposeful interactive process can be known as interactive marketing. Its core is interaction participants communicate each other, create value collectively and achieve win-win results. In this paper, interaction quality is divided into employee- customer interaction quality and enterprise- customer interaction quality.

The Relationship between Interaction Quality and Brand Equity. (1) The relationship between interaction quality and brand recognition. Brand recognition is the value that products or service brings to customers in the process of interaction between customers and brands. Through showing customers environment, atmosphere, culture and brand knowledge, it forms customers' awareness to brands, and affects customers' overall evaluation to brands. In the process of employees explaining brand knowledge, demonstrating products' features to customers and guiding 
customers to use products, interaction quality directly affects brand function, brand experience and brand image. So hypotheses are:

H1: Enterprise- customer interaction quality impact on brand function, brand experience and brand image positively.

H2: Employee- customer interaction quality impact on brand function, brand experience and brand image positively.

(2) The relationship between interaction quality and brand emotion. Brand emotion is emotional attitude produced in the process of interaction between customers and brands, and it includes brand promise and brand attachment. The overall strength enterprises shown and the professional quality of employees influence customers' confidence in brands, and form preference or disgust on customers to brands. High-quality interaction enhances customers' willingness to build lasting relationship with brands and forms brand attachment. So hypotheses are:

H3: Enterprise- customer interaction quality impact on brand promise and brand attachment.

H4: Employee- customer interaction quality impact on brand promise and brand attachment.

(3) The relationship between interaction quality and brand loyalty. Brand loyalty is customers' consumption tendency to brands. All things enterprises and employees shown customers could influence customers' purchase intention and purchase behavior. Existing research results shown that the interaction quality has a positive effect on brand loyalty ${ }^{[3]}$. Therefore, this paper puts forward the following hypotheses:

H5: Enterprise- customer interaction quality impact on brand promise and brand attachment.

H6: Employee- customer interaction quality impact on brand promise and brand attachment.

Thus, the theory of model show in fig. 1:

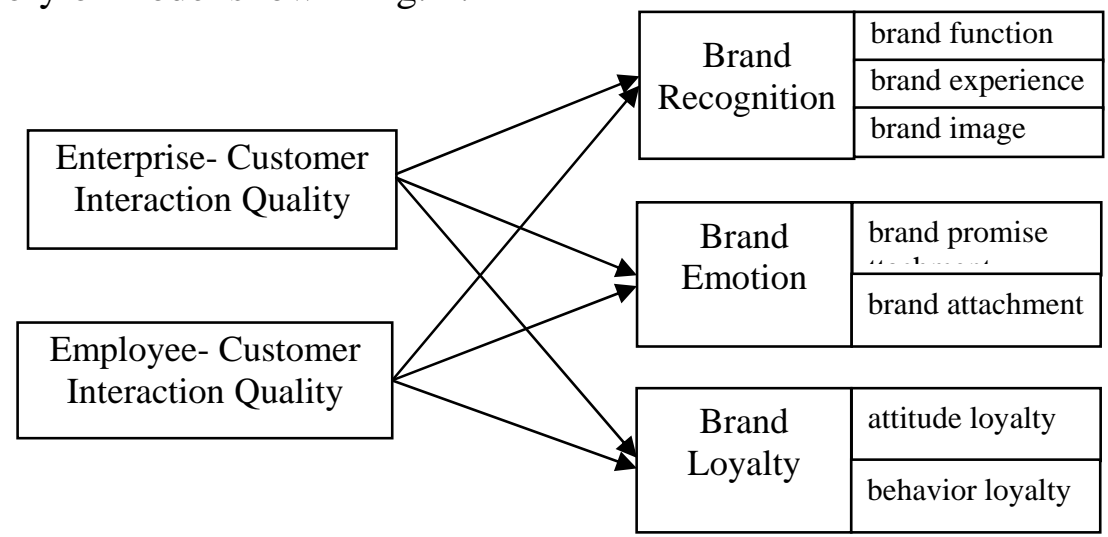

Fig. 1: Brand Equity Driving Model Based on Interaction Quality

\section{The Empirical Analysis and Results}

Sample and Data Collection. In this paper, the specific automobile brand is research object. The reasons are: (1) For automobile brands, customers spend more energy to collect information through enterprises' publicity, BBS, asking others, experience to 4s shops or other interactive way before making a purchase decision; (2) Auto industry follows the principle of users first, and interaction runs through information collection, purchasing and after-sales service, so interaction has a impact on brand equity; (3) automobile brand is highly mixed brand of service and products. Therefore, choosing automobile brands to test the model of this paper has certain representativeness. In this research, 300 questionnaires were sent out, and 216 effective questionnaires were taken back, and effective rate was $72 \%$.

Reliability Analysis and Validity Analysis. In order to ensure the reliability of research conclusion, reliability analysis and validity analysis of internal consistency is necessary. The test results are shown in table 1 . Cronbach's Alpha of every element was greater than 0.65 , and Cronbach's Alpha of the questionnaire is 0.870 . It shows internal consistency is passed. KMO of every element in the model is greater than 0.62 and Bartlett's Test is 0.000 . It shows that there is a correlation between data. Then adopt Variance and get the cumulative variance proportion which is 
greater than $40 \%$.

Table 1 the Results of Reliability and Validity

\begin{tabular}{llllll}
\hline Variable & N & Cronbach's Alpha & KMO & Variance Proportion[\%] & Bartlett's Test \\
Enterprise- Customer Interaction Quality & 6 & 0.743 & 0.785 & 44.254 & 0.000 \\
Employee - Customer Interaction Quality & 6 & 0.767 & 0.738 & 47.308 & 0.000 \\
Brand Function & 3 & 0.771 & 0.700 & 68.822 & 0.000 \\
Brand Experience & 3 & 0.659 & 0.649 & 59.701 & 0.000 \\
Brand Image & 3 & 0.706 & 0.675 & 63.045 & 0.000 \\
Brand Promise & 3 & 0.681 & 0.624 & 61.455 & 0.000 \\
Brand Attachment & 3 & 0.741 & 0.673 & 65.895 & 0.000 \\
Attitude Loyalty & 3 & 0.866 & 0.638 & 79.090 & 0.000 \\
Behavior Loyalty & 3 & 0.910 & 0.643 & 85.315 & 0.000 \\
\hline
\end{tabular}

Cronbach's Alpha of the questionnaire: $0.870, \quad \mathrm{~N}=51$

Correlation Analysis. This paper uses Pearson Correlation Coefficient of correlation analysis to research the relation between variables. The greater the absolute value of coefficient, the more relevant between variables. The results are shown in table 2 .

Table 2 the Results of Correlation Analysis

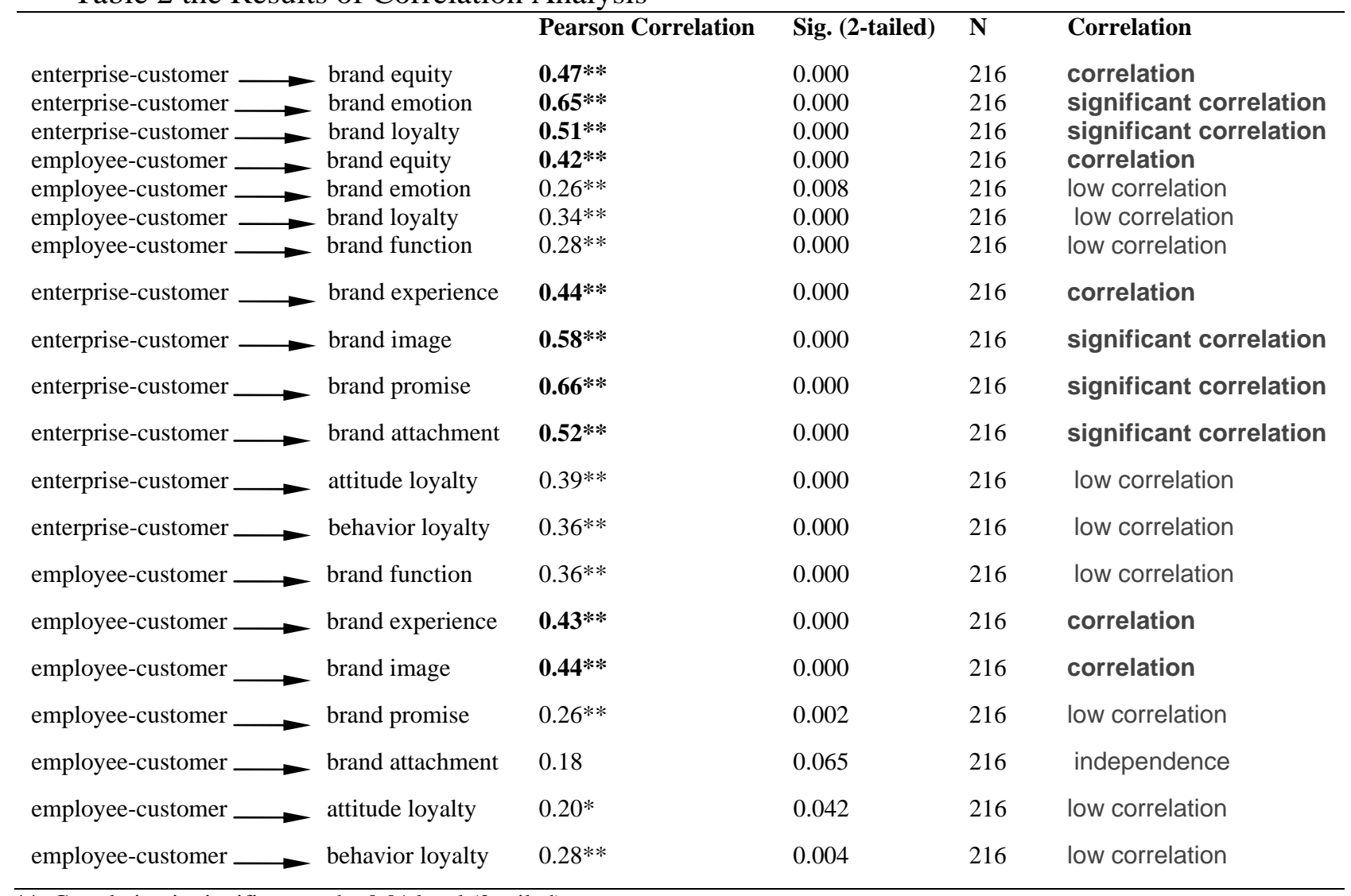

**. Correlation is significant at the 0.01 level (2-tailed).

According to above results, draw the brand equity driving model diagram. It is shown in fig. 2. 


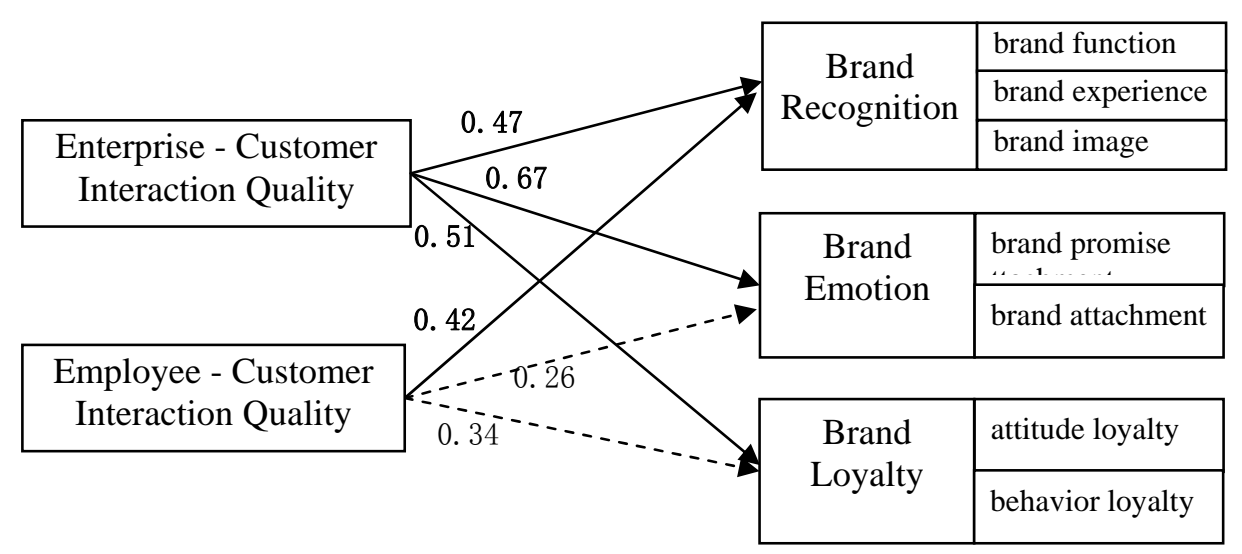

Fig. 2 Brand Equity Driving Model Based on Interaction Quality

\section{Research Conclusions and Limitations}

Conclusions and Discussion. The survey take the specific automobile brand as the research object, and explore a brand equity driving model based on interaction quality in the way of empirical study. The main conclusions are:

(1)Interaction quality is the important driving factor of brand equity. The interaction quality is composed of enterprise - customer interaction quality and employee - customer interaction quality, and brand equity can be divided into brand cognition, brand emotion and brand loyalty. The empirical results show that enterprise - customer interaction quality has prominent influences on three dimensions of brand equity and the influence coefficients are 0.47, 0.65 and 0.51. Employee customer interaction quality impacts on brand recognition most significant, and impacts on the brand emotion and brand loyalty less.

(2) Enterprise - customer interaction quality impact on all elements of brand equity positively, especially on brand experience, brand image, brand promise and brand attachment. High quality interaction between enterprises and customers affects all levels of brand equity, and promotes the brand equity. As the coming of the Internet, for the cost getting information greatly reduced, customers can easily know brand information, so only rely on perfect brand function to move customers is hard, and the effect of brand experience and emotional preference is more and more obvious. The relationship between enterprise and customer is equal and mutual benefit in the new era. In the current situation, enterprises should improve enterprise- customer interaction quality, design brand function and choose the way of brand information communication for customeroriented, and also according to customers' feedback to adjust and improve at any time. Meanwhile on the basis of perfecting brand function, always put customer experience and emotional benefits in the first place. With the help of a variety of ways of interaction to create good customer experience and strengthen the brand image, and make customers to rely on the brand in emotion, then stimulate the value of brand equity.

(3) Employee- customer interaction quality impacts on brand experience and brand image positively. However, it has no influence on brand attachment and has no significant influence on other factors of brand equity. It shows interaction quality affects the customers' recognition of brands more and has little effect on customers' emotional attitude and purchase decision. So employees should first improve the intensity and frequency of communication with customers, and increase communication forms and make customers understand and actively spread the brand culture through using network platform such as Microblog, WeChat and BBS. Meanwhile in the process of interacting with customers, employees should establish a good image, pay attention to the customers' feelings and communicate with customers sincerely. Also guide customers to experience products, always focus on improving customer experience and brand image and make the customer satisfied among interaction, then improve customers' brand awareness and enhance the brand equity finally. 
Contributions and Limitations. In this paper, a brand equity driving model was proposed based on interaction quality and tested by a specific automobile brand. The contributions of this study are: The first, it defines the concept of interaction and interactive marketing to lay the foundation for the later research. The second, it divides brand equity into three dimensions and seven elements based on interactive quality more clearly. The third, it explores the effects degree of interaction quality to every dimension of brand equity through the empirical analysis, and makes enterprises confirm the key to promoting brand equity: Enterprises should enhance customers' brand awareness, brand emotion and brand loyalty by improving enterprise- customer interaction quality, and focus on enhancing brand experience and brand image by improving employee- customer interaction quality. In addition, although most of conclusions of the paper are supported, there are still some limitations and need further research in the future. Firstly the study selected a specific automobile brand, not involve the whole industry or other industries. In the later study, a few more representative industries can be chose. Secondly the sample was collected in local market and didn't consider regional and cultural differences, so it needs to further demonstrate whether the conclusions of this research are suitable in wide areas.

\section{References}

[1] Bateson E G. Perceived Control and the Service Encounter [M]. USA: Lexington Books, 1985, 76.

[2] Ambler T. Marketing and the Bottom Line: The New Metrics of Corporate Wealth [M]. London: Financial Times /Prentice Hal, 2000.

[3] Haiying Wei, Lei Zhang. A Service Brand Equity Driving Model Based on Multi-dimension Interaction [J]. Economic Management, 2010, (5): 151 158. In Chinese

[4] Kim P. A Perspective on Brands[J]. Journal of Consumer Marketing, 1990, 7(4): 20 31.

[5] Keller K L. Brand Synthesis: The multidimensionality of Brand Knowledge [J]. Journal of Consumer Research, 2003, 29 (4): 595 600.

[6] Gil R B, Andres E F, and Salinas E M. Family as Source of Consumer-Based Brand Equity [J].Journal of Product \& Brand Management, 2007, 16(3):188 199.

[7] Feng Zhang. A Review and Construct of a New Model for Customer-Based Brand Equity[J]. Chinese Journal of Management, 2011, 8(4): 552 576. In Chinese

[8] Guihua Li, Hongliang Lu. Spillover Value of the Suppliers’ Brand, Brand Relationship Quality and Buyers' Repurchase Intention: From the Perspective of Buyers [J]. Nankai Business Review, 2010, 13(4): 71 82. In Chinese 